\title{
Polymorphism of the insulin gene is associated with increased prostate cancer risk
}

\author{
GYF Ho*,', A Melman', S-M Liu', M Li ${ }^{3}, \mathrm{H} \mathrm{Yu}^{6}$, A Negassa', RD Burk ${ }^{4}$, AW Hsing ${ }^{7}, \mathrm{R}$ Ghavamian ${ }^{2}$ and \\ SC Chua Jr $\mathbf{5}^{\mathbf{5}}$
}

'Department of Epidemiology and Social Medicine, Albert Einstein College of Medicine, Bronx, New York, NY I046I, USA; ${ }^{2}$ Department of Urology, Albert Einstein College of Medicine, Bronx, New York, NY 1046I, USA; ${ }^{3}$ Department of Pathology, Albert Einstein College of Medicine, Bronx, New York, NY 1046I, USA; ${ }^{4}$ Department of Pediatrics, Albert Einstein College of Medicine, Bronx, New York, NY 10461, USA; ${ }^{5}$ Division of Molecular Genetics, Department of Pediatrics, Columbia University, New York, NY 10032, USA; ${ }^{6}$ Department of Epidemiology and Public Health, Yale University, New Haven, CT 06520, USA; ${ }^{7}$ Division of Cancer Epidemiology and Genetics, National Cancer Institute, Bethesda, MD 20852, USA

\begin{abstract}
High insulin levels are linked with increased cancer risk, including prostate cancer. We examined the associations between prostate cancer with polymorphisms of the insulin gene (INS) and its neighbouring genes, tyrosine-hydroxylase and IGF-II (TH and IGF2). In this study, 126 case-control pairs matched on age, race, and countries of origin were genotyped for + I I 27 INS-Pstl in INS, -42 I7 TH-PstI in TH, and +3580 IGF2-Mspl in IGF2. The homozygous CC genotype of +1 I 27 INS-Pstl occurred in over $60 \%$ of the population. It was associated with an increased risk of prostate cancer in nondiabetic Blacks and Caucasians $(O R=3.14, P=0.008)$. The $C C$ genotype was also associated with a low Gleason score $<7(\mathrm{OR}=2.60, P=0.022)$ and a late age of diagnosis $(\mathrm{OR}=2.10$, $P=0.046)$. Markers in the neighbouring genes of INS showed only null to modest associations with prostate cancer. The polymorphism of INS may play a role in the aetiology of prostate cancer. Given the high prevalence of the CC genotype and its association with late age of onset of low-grade tumours, this polymorphism may contribute to the unique characteristics of prostate cancer, namely a high prevalence of indolent cancers and the dramatic increase in incidence with age.

British Journal of Cancer (2003) 88, 263-269. doi:I 0.I038/sj.bjc.6600747 www.bjcancer.com

(C) 2003 Cancer Research UK
\end{abstract}

Keywords: prostate cancer; insulin; polymorphism

The insulin-like growth factor (IGF) system, which includes two ligands (IGF-I and IGF-II), two cell membrane receptors (IGF-1R and IGF-2R), six binding proteins (IGFBP-1 through IGFBP-6), and a large group of IGFBP proteases (Grimberg and Cohen, 2000; Khandwala et al, 2000; Yu and Rohan, 2000), has been implicated in carcinogenesis because of its important role in regulating cell proliferation, differentiation, apoptosis, and transformation (Grimberg and Cohen, 2000). There are several consistent reports that link risk of prostate cancer with high serum levels of IGF-I (Mantzoros et al, 1997; Chan et al, 1998; Wolk et al, 1998; Stattin et al, 2000; Chokkalingam et al, 2001). Decreased levels of IGFBP-3, the most abundant IGFBP in the circulation, have been found in prostate cancer patients and in those with metastatic diseases (Kanety et al, 1993; Chan et al, 1998; Chokkalingam et al, 2001).

Insulin is hypothesised as a risk factor of prostate cancer because of its structural and regulatory relations with the IGF system. There is structural homology among insulin, IGF-I, and IGF-II as well as between insulin receptor and IGF-1R (Khandwala et al, 2000; Yu and Rohan, 2000), so insulin and IGFs can crossbind

*Correspondence: Dr GYF Ho, Department of Epidemiology and Social Medicine, Albert Einstein College of Medicine, 1300 Morris Park Avenue, Belfer Building, Room 1312, Bronx, NY 1046I, USA;

E-mail: ho@aecom.yu.edu

Received 8 May 2002; revised 5 November 2002; accepted II November 2002 to each other's receptor although with weak affinity (Efstratiadis, 1998). Insulin regulates IGFBP-1 and may affect circulating levels of free IGFs (Powell et al, 1991). In addition to its close relation with the IGF system, the negative correlation between high insulin and decreased sex hormone-binding protein (SHBP) may result in increased levels of free testosterone (Strain et al, 1994; Pasquali et al, 1995). So far, only one study in prostate cancer has examined serum insulin levels using fasting blood. In this case-control study conducted in China, men with insulin levels in the highest tertile had a 2.5 -fold increased risk of prostate cancer compared to men in the lowest tertile after adjusting for IGF-I and anthropometric factors (Hsing et al, 2001). One of the causes for elevated insulin levels might be genetic variation in the insulin gene (INS). We examined the relation between risk of prostate cancer and a single nucleotide polymorphism (SNP) marker in INS in a case-control study.

The insulin gene is located on chromosome 11 (11p15.5). The variable number of tandem repeat (VNTR) that lies immediately adjacent to the $5^{\prime}$ promoter region of INS is believed to have a direct effect on INS regulation (Kennedy et al, 1995). The polymorphism of the VNTR can be classified into two main groups: small class I alleles (28-44 repeats) and large class III alleles (138-159 repeats) at frequencies of about 70 and $30 \%$, respectively, and class II alleles of intermediate size are rare (Stead and Jeffreys, 2000). The class I allele is associated with increased expression of insulin mRNA and insulin levels (Lucassen et al, 1995; Bennett and Todd, 1996; Le Stunff et al, 2000). The allelic variation of VNTR is also associated with the risk of diabetes. It 


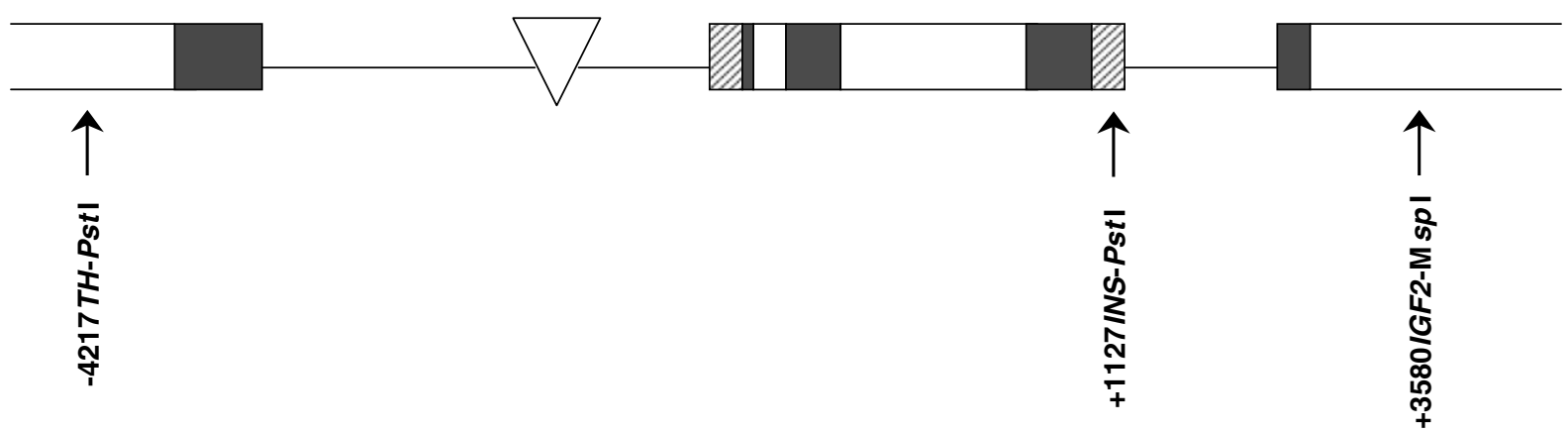

Figure I Position of SNPs examined in the TH-INS-IGF2 region on chromosome I | p I5.5. This 19-kb genomic region, in which 19 polymorphisms have been identified, includes the tyrosine hydroxylase (TH), insulin (INS), and IGF-II (IGF2) genes (Lucassen et al, I 993). Three SNPs were examined in this study and are designated by their position (the positive and negative numbers indicate the number of base pairs downstream and upstream from the initiator codon of INS, respectively), corresponding gene, and the restriction enzyme used for detection: (a) - 42I7 T/C polymorphism of TH detected by Pstl, (b) + I 127 T/C polymorphism of INS detected by Pstl, and (c) +3580 G/A polymorphism of IGF2 detected by Mspl. Open, closed, and hatched boxes refer to introns, exons, and untranslated regions, respectively. The triangle represents the variable number of tandem repeat (VNTR) locus adjacent to the promoter region of INS. Figure not drawn to scale.

has been found consistently that the class I allele increases the risk of type I diabetes (Julier et al, 1991; Lucassen et al, 1993; Bennett and Todd, 1996). An association between the class III allele and type II diabetes has also been reported (Ong et al, 1999). In addition to the VNTR, there are 10 noncoding SNP markers that span the $4.1 \mathrm{~kb}$ segment of the entire INS gene and its flanking intergenic regions. It has been shown in Caucasian populations that these 10 SNPs are in tight linkage disequilibrium with each other and with the VNTR such that they constitute two major haplotypes (Cox et al, 1988; Julier et al, 1991; Lucassen et al, 1993). In such a region of tight linkage disequilibrium, assaying for one marker would generally provide genotype information of all the others. We assayed for two of these SNP markers, the +1127 INS-PstI and +1428 INS-FokI (the positive number indicates the number of base pairs downstream from the initiator codon of INS), as the surrogates for the VNTR. We found complete concordance for genotypes at these two markers in 50 subjects tested. Here, we reported the results of the PstI marker in the entire study population. The PstI marker was chosen for genotyping, since it was reported to be in complete linkage disequilibrium with three other SNPs in the INS genomic region, and genotypes for this marker were almost always identical to those at the VNTR (Lucassen et al, 1993). To further show that INS, rather than adjacent genes on chromosome 11, is indeed the risk-associated gene, we also genotyped two markers in the tyrosine-hydroxylase and IGF-II genes (TH and IGF2), which flank the $5^{\prime}$ and $3^{\prime}$ ends of INS, respectively (Figure 1).

\section{MATERIALS AND METHODS}

In this case-control study, cases with histopathologically confirmed prostate cancer were identified from two hospitals affiliated with the Albert Einstein College of Medicine. They were private patients either diagnosed or treated at the Departments of Urology in these hospitals. After obtaining a physician's approval, sequential patients who had no history of other cancers were recruited within a year of diagnosis. For potential controls, outpatients who were male and $\geqslant 40$ years old were randomly sampled from the billing records of the Departments of Medicine in the same hospitals where the cases arose. Patients who had no history of any cancer and had intact prostate and testes formed a pool of eligible controls. The reasons for seeing an internist were not used as exclusion criteria. One control was matched to each case on birth year ( \pm 5 years), race, and countries of origin. Questionnaire data and nonfasting blood samples were obtained. DNA was extracted from whole blood and genotyped for three markers in the TH-INS-IGF2 region (Figure 1) by a polymerase chain reaction-based restriction fragment length polymorphism assay (PCR-RFLP). The study protocol was approved by the institutional review board, and informed consent was obtained from all subjects.

Between 1998 and 2000, 191 cases and 148 controls were recruited. Genotyping was performed on 178 (93\%) cases and 135 (91\%) controls who had a DNA sample. Odds ratios for the associations between polymorphisms and risk of prostate cancer were estimated by conditional logistic regression in 126 casecontrol pairs. A total of 52 cases were excluded from conditional logistic regression analyses either because a control who fulfilled the three matching factors was not available or the matched control did not have genotype data. They were not different from the 126 analysable cases in terms of age at diagnosis, Gleason score, race, and genotype frequencies. Moreover, using all the recruited cases and controls in unmatched analyses yielded similar results. The results from conditional logistic regression were presented, since it is the appropriate and standard statistical method for analysing matched case-control data.

To examine the effects of the INS polymorphism on two diagnostic characteristics, namely Gleason score $(<7$ or $\geqslant 7)$ and age at diagnosis $(<55,55-64$, or $\geqslant 65)$, case-case analyses were performed among all the 178 cases. The cut point for Gleason score was chosen for its association with tumour extent, prognosis, and survival (Kattan et al, 1997; D'Amico et al, 1998). Treating Gleason score and age at diagnosis as the outcome variables, logistic regression analyses for dichotomous and ordinal dependent variables, respectively, were performed to examine their associations with the INS polymorphism while controlling for confounding variables. Data were analysed by the statistical software package SAS (SAS Institute Inc., 1989). All $P$-values presented are two-sided.

Three SNPs in three genes were genotyped in this study. To measure the extent of linkage disequilibrium between any pairwise markers, we first inferred phase and reconstructed haplotypes using the PHASE software (http://www.stat.washington. edu/stephens/phase.html) developed by Stephens et al (2001). Linkage disequilibrium was measured by $D^{\prime}$ (Devlin and Risch, 1995). 


\section{PCR-RFLP assays for detection of polymorphisms}

Primers to amplify the three genomic regions are:

$\begin{array}{ll}I N S+1035 & \text { GGG TCC CCT GCA GAA GCG TGG CA } \\ I N S+1597 & \text { CTC CCT CCA CAG GGA CTC CAT C } \\ T H-P s t \mathrm{~F} & \text { TGA CGC CAA GGA CAA GCT CAG GT } \\ T H-P s t \mathrm{R} & \text { CCA CCC AGC AGC CCC AGT CCT GT } \\ I G F 2-M s p \mathrm{~F} & \text { CCA CCC CTT CTG GGA AGC TAA AAG } \\ I G F 2-M s p \mathrm{R} & \text { CCC TCG GTC CTC CAG GAA TGG ACA }\end{array}$

The TH and IGF2 amplicons were amplified using standard Taq DNA polymerase with cycling plateaus of $94^{\circ}-55^{\circ}-72^{\circ}$ for 30 seconds each ( 35 cycles). The INS amplicon was more refractory to reliable amplification with Taq DNA polymerase. We used LA Taq, a DNA polymerase mix, with a proofreading enzyme in order to obtain reliable amplification. Amplified DNA $(5 \mu \mathrm{l})$ was used in a $10 \mu \mathrm{l}$ restriction enzyme digest with $1-2 \mathrm{U}$ of enzyme using the manufacturer's recommendations. Digested products were size fractionated on high percentage agarose gels and visualised by UVinduced ethidium fluorescence. The restriction fragments of the alleles are as follows:

INS T allele $562 \mathrm{bp}$

C allele $470 \mathrm{bp}+92 \mathrm{bp}$

TH T allele $240 \mathrm{bp}$

$\mathrm{C}$ allele $148 \mathrm{bp}+92 \mathrm{bp}$

IGF2 A allele $122 \mathrm{bp}+118 \mathrm{bp}$

G allele $122 b p+84 b p+34 b p$

\section{RESULTS}

The age at diagnosis of the prostate cancer cases ranged from 43 to 88 years, with a median at 63 . The majority of the cases $(77 \%)$ were diagnosed due to an abnormal PSA test or digital rectal examination. The ethnic distribution of the cases was 54\% African Americans, 22\% Caucasians, 21\% Hispanics, and 3\% others, reflecting the ethnic distribution of the population in the catchment area. Genotype frequencies of the three markers in the TH-INS-IGF2 region by ethnicity are presented in Table 1 . The +1127 INS-PstI marker was in linkage disequilibrium with both 4217 TH-PstI and +3580 IGF2-MspI in the neighbouring genes (Table 1). The $\mathrm{C}$ alleles of -4217 TH-PstI were linked to the $\mathrm{C}$ alleles of +1127 INS-PstI, resulting in a linkage disequilibrium score $\left(\mathrm{D}^{\prime}\right)$ of one; the two markers, however, were not in complete linkage disequilibrium. For +1127 INS-PstI, the homozygous CC was the predominant genotype. The heterozygous CT and homozygous TT were grouped together as the 'other genotypes' in analyses due to small numbers.

Table 2 shows that individuals with homozygous CC for +1127 INS-PstI had almost a two-fold increased risk of prostate cancer as compared to those with other genotypes $(\mathrm{OR}=1.74)$. As the polymorphism at +1127 INS-PstI and its tightly linked VNTR have been reported to be associated with diabetes (Lucassen et al, 1993), we first stratified the analysis by diabetes status, which was based on self-report. There was a disparity by diabetes status, such that the association between +1127 INS-PstI and prostate cancer was apparent among subjects without diabetes $(\mathrm{OR}=2.18)$ but not among those with diabetes $(\mathrm{OR}=1.13)$. Subsequent analyses were then limited to case-control pairs in which both members were nondiabetic. We then evaluated if there was heterogeneity in disease association by ethnicity. Stratified analyses by ethnicity showed that association existed among the nondiabetic Black subjects $(\mathrm{OR}=2.75)$ and Caucasians $(\mathrm{OR}=3.67)$, but not the Hispanics $(\mathrm{OR}=0.25)$. The sample size for the Hispanics was small, and their genotype frequencies of +1127 INS-PstI were also not in Hardy-Weinberg equilibrium. The genetic effect was agedependent: the strongest association between the CC genotype and increased risk of prostate cancer occurred among subjects who were Black or Caucasian and $\geqslant 55$ years old (ORs for $<55,55-64$, and $\geqslant 65=0.75,5.0$, and 9.0, respectively).

Table 1 showed that linkage disequilibrium existed between +1127 INS-PstI and the two markers in the flanking neighbouring genes. It is possible that a locus adjacent to INS is in fact the disease-associated gene, and the observed association with +1127 INS-PstI is due to linkage disequilibrium between polymorphisms of the disease-associated gene and INS. If so, polymorphism of the

Table I Percent distributions of the genotypes and pairwise linkage disequilibrium scores for three markers in the TH-INS-IGF2 region stratified by ethnicity

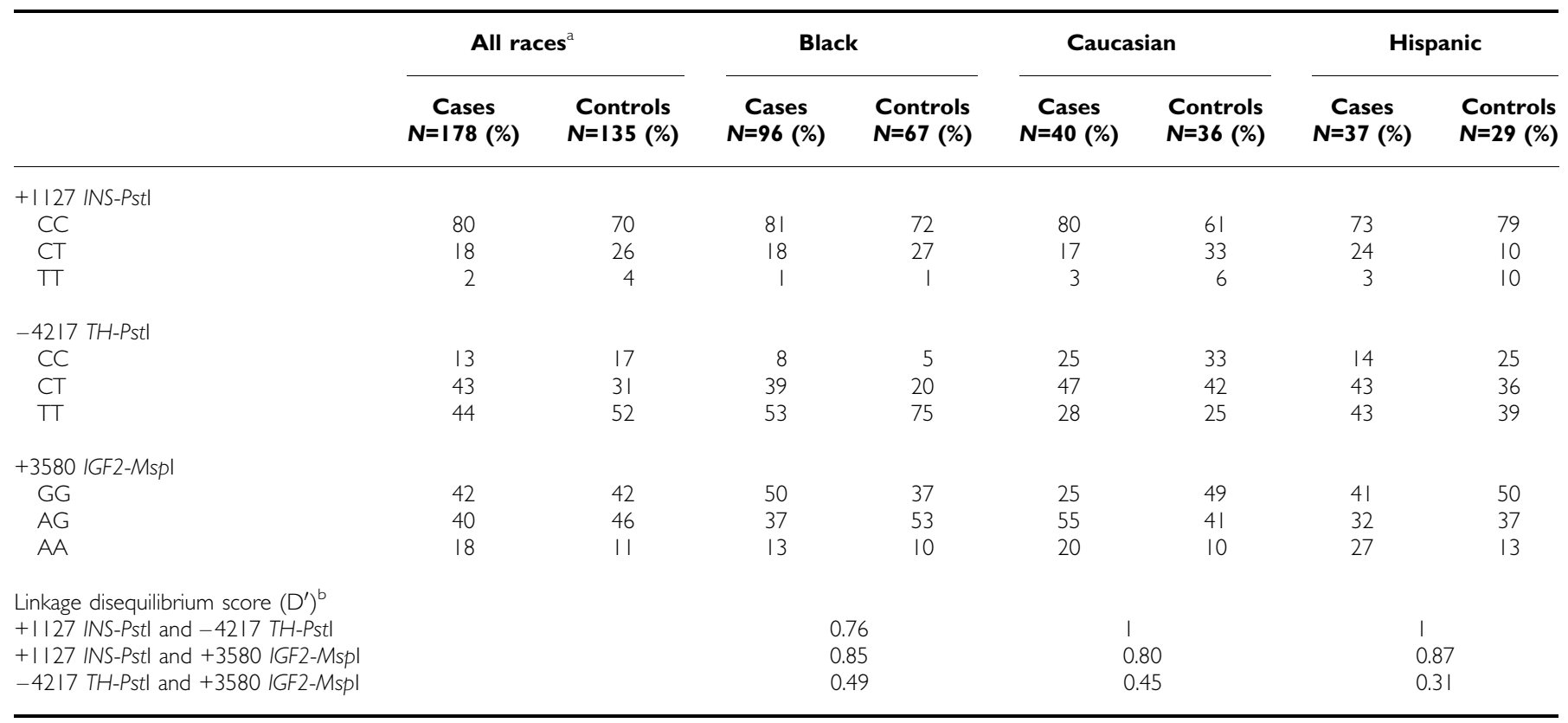

${ }^{a}$ Subjects with mixed ethnicity were included here, but not in the race-specific columns. ${ }^{b} D^{\prime}$ was determined with cases and controls combined. 
Table 2 Odds ratios for the association between prostate cancer and the homozygous CC genotype of + I I 27 INS-Pstl

\begin{tabular}{lccc}
\hline & No of pairs & OR (95\% Cl) & P-value \\
\hline All subjects & 126 & $1.74(0.99-3.05)$ & 0.055 \\
By diabetes status & & $2.18(1.07-4.45)$ & 0.032 \\
$\quad$ No & 86 & $1.13(0.43-2.92)$ & 0.809 \\
$\quad$ Yes & 40 & $2.75(0.88-8.64)$ & 0.083 \\
By race, among nondiabetics & & $3.67(1.02-13.14)$ & 0.046 \\
$\quad$ Black & 45 & $0.25(0.03-2.24)$ & 0.215 \\
$\quad$ Caucasian & 26 & $3.14(1.34-7.36)$ & 0.008 \\
$\quad$ Hispanic & 14 & $0.75(0.17-3.35)$ & 0.706 \\
Black and Caucasian, among nondiabetics & 71 & $6.33(1.87-21.4)$ & 0.003 \\
By age, among nondiabetic Black and Caucasian & & & \\
$\quad<55$ & 14 & 57 &
\end{tabular}

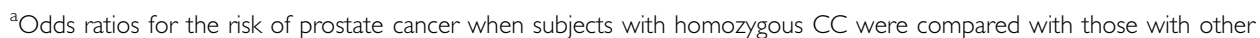
genotypes (the heterozygous and homozygous TT), with the latter as the reference group. ${ }^{b}$ One or both members of the pair had diabetes. 'The case's age at diagnosis was used for classification of the pair. P-value for homogeneity of odds ratios (i.e. interaction between age and the + I 27 INS-Pstl polymorphism) $=0.030$.

Table 3 Associations between prostate cancer and three markers in the TH-INS-IGF2 genomic region - among non-diabetic Black and Caucasian subjects ( $n=68$ pairs)

\begin{tabular}{llc}
\hline & $\begin{array}{c}\text { Adjusted OR } \\
(\mathbf{9 5 \%} \mathbf{~ C I})^{\mathrm{a}}\end{array}$ & $\boldsymbol{P}$ \\
\hline$+\mid 127$ INS-Pstl & & \\
CT or TT & 1 & 0.010 \\
CC & $3.57(1.35-9.45)$ & \\
-4217 TH-Pstl & & 0.053 \\
TT & 1 & 0.355 \\
CT & $2.27(0.99-5.19)$ & \\
CC & $1.72(0.55-5.42)$ & \\
$+3580|G F 2-M s p|^{b}$ & & 0.797 \\
GG & 1 & 0.559 \\
AG & $0.90(0.42-1.95)$ & \\
AA & $1.52(0.37-6.27)$ & \\
\hline
\end{tabular}

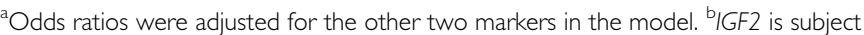
to parental imprinting, and only the paternal allele is expressed. OR for the heterozygous genotype was difficult to interpret, when the expressing allele (A or G) was not identified. Conversely, knowing the active allele among the subjects with homozygous AA or GG was irrelevant. Hence, the OR for the homozygous AA was fully interpretable when the homozygous GG was used as the reference. disease-associated gene should demonstrate a stronger association with prostate cancer than +1127 INS-PstI. Table 3 shows that prostate cancer remained to have the strongest association with the CC genotype of +1127 INS-PstI ( $\mathrm{OR}=3.57)$; the associations with -4217 TH-PstI (CT $v s$ TT, OR $=2.27$ ) and +3580 IGF2-MspI (AA $v s$ $\mathrm{GG}, \mathrm{OR}=1.52$ ) were comparatively moderate. Moreover, the association between -4217 TH-PstI and prostate cancer was attributed to the heterozygous genotype, the OR did not increase for the homozygous, and hence the association lacked a genedosage trend.

In Table 4, the case-case analyses showed that prostate cancer patients with the CC genotype, as compared to those with other genotypes, were more likely to have a low Gleason score $<7$ $(\mathrm{OR}=2.60)$ after controlling for variables that were significantly associated with Gleason score, namely age at diagnosis and frequency of seeing a physician for physical examination. The CC genotype was also associated with a late age of diagnosis $(\mathrm{OR}=2.10)$ after adjusting for Gleason score and frequency of physical examination.

\section{DISCUSSION}

The role of insulin in the aetiology of prostate cancer is implicated by the observations from this and another study in China that increased risk of prostate cancer was associated with genetic

Table 4 Associations between homozygous CC genotype of + I I 27 INS-Pstl and characteristics of prostate cancer at diagnosis

\begin{tabular}{lcccc}
\hline $\begin{array}{c}\text { Dependent } \\
\text { variable }\end{array}$ & $\begin{array}{c}\text { Number of } \\
\text { cases }\end{array}$ & $\begin{array}{c}\text { Percent with } \\
\text { homozygous CC }\end{array}$ & $\begin{array}{c}\text { Univariate } \\
\text { P-value }\end{array}$ & $\begin{array}{c}\text { Adjusted } \\
\text { OR (95\% CI) }\end{array}$ \\
\hline $\begin{array}{l}\text { Gleason score } \\
2-6\end{array}$ & 116 & & & $\begin{array}{c}\text { Multivariable } \\
\text { P-value }\end{array}$ \\
$\geqslant 7$ & 52 & 84 & 0.034 & $2.60(1.15-5.88)^{\mathrm{a}}$ \\
$\begin{array}{l}\text { Age at diagnosis } \\
<55\end{array}$ & 26 & 69 & & 0.022 \\
$55-64$ & 72 & 69 & & $2.10(1.01-4.33)^{\mathrm{c}}$ \\
$\geqslant 65$ & 80 & 79 & $0.121^{\mathrm{b}}$ & 0.046 \\
\hline
\end{tabular}

${ }^{a}$ Odds ratios for the risk of having a low Gleason score $<7$ were obtained from logistic regression analysis, when the subjects with homozygous $\mathrm{CC}$ were compared with those with other genotypes (reference category). Odds ratio was adjusted for age at diagnosis $(<55,55-64$, or $\geqslant 65$ ) and frequency of seeing a doctor for physical examination (less than once a year, once a year, or more than once a year). ${ }^{b} P$ for trend. ${ }^{c}$ Odds ratios were estimated from ordinal logistic regression analysis. The positive odds ratio (2. I0) indicates that the subjects with homozygous CC were more likely to be in a higher category of age at diagnosis (i.e. diagnosed at a later age) than subjects with other genotypes. The odds ratio was adjusted for Gleason score $(2-6$ or $\geqslant 7)$ and frequency of seeing a doctor for physical examination. 
variation in INS, but not its neighbouring genes, as well as elevated fasting insulin levels (Hsing et al, 2001). Epidemiological studies have also found a positive correlation between insulin levels and risk of various cancers, such as colon, breast, and endometrial cancers (Maggino et al, 1993; Gamayunova et al, 1997; Troisi et al, 1997; Del Giudice et al, 1998; Schoen et al, 1999; Josefson, 2000; Kaaks et al, 2000; Yang et al, 2001; Goodwin et al, 2002). Biological mechanisms that support the tumorigenic effects of insulin include the following: (a) Insulin regulates and stimulates cell growth through binding to its receptor (Van Obberghen and Gammeltoft, 1986; Denton and Tavare, 1995; Moule and Denton, 1997). However, mitogenicity appears to occur at supraphysiologic levels of insulin. (b) It inhibits apoptosis in different cellular models (Park et al, 2000; Qian et al, 2001). (c) Insulin, IGF-I and IGF-II share about $50 \%$ structural homology, and there is $60 \%$ homology between insulin receptor and IGF-1R. Insulin and IGFs can crossbind to each other's receptor or to hybrid insulin and IGF-I receptors, although the affinity is weak (Soos et al, 1990; Efstratiadis, 1998). In some in vitro studies, the growth-promoting effects of insulin are mediated primarily by its low-affinity interaction with IGF-1R (Straus, 1984). (d) Insulin is the primary regulator of IGFBP-1. It inhibits transcription of IGFBP-1, and this may increase unbound, circulating IGFs (Powell et al, 1991). (e) Insulin decreases the synthesis of (SHBP) and may thereby increase the bioavailability of free steroids (e.g. testosterone) for hormone-dependent tissues like the prostate (Strain et al, 1994; Pasquali et al, 1995).

The +1127 INS-PstI marker is located in the $3^{\prime}$ untranslated region (UTR) of INS, and the UTR regions of the preproinsulin mRNA have recently been demonstrated to play crucial roles in regulating insulin production. The $3^{\prime}$-UTR of INS suppresses translation and also stabilizes the mRNA. It acts cooperatively with the $5^{\prime}$-UTR and markedly increases glucose-induced proinsulin biosynthesis (Wicksteed et al, 2001). Therefore, the polymorphism at +1127 INS-PstI, although located in an untranslated region, may have a functional effect on the expression of INS.

The +1127 INS-PstI polymorphism may also be in intragenic linkage disequilibrium with a causal mutation in INS. In Caucasian populations in the US and Europe, the +1127 INS-PstI polymorphism and nine other noncoding markers within the INS region are in tight linkage disequilibrium with the VNTR locus, which is located only $365 \mathrm{bp}$ from the start of transcription for insulin (Cox et al, 1988; Julier et al, 1991; Lucassen et al, 1993). The class I allele of the VNTR is related to overexpression of insulin mRNA and increased insulin levels in some studies (Lucassen et al, 1995; Bennett and Todd, 1996; Le Stunff et al, 2000). The C allele of +1127 INS-Pst I, which was associated with increased risk of prostate cancer in this study, is linked with the class I allele of the VNTR. The extent of linkage disequilibrium across the insulin gene and VNTR, however, has never been studied in the Blacks or Hispanics. Hence it is not known if +1127 INS-PstI is also a surrogate for the VNTR in the non-Whites in this study. Nevertheless, the significant linkage disequilibrium in the Caucasians suggests a strong evolutionary selection (Lucassen et al, 1993), and it is likely that strong linkage disequilibrium also exists in other populations as has been shown in a Chinese population (Cox et al, 1988).

Finally, there remains the possibility that INS is not the riskassociated gene, and that +1127 INS-PstI is in linkage disequilibrium with another marker in a disease-causing gene. It is unlikely, since INS showed the strongest association with risk of prostate cancer, as the strength of association dropped off with the two neighbouring genes. It is, however, not surprising to see residual association between prostate cancer and the CT genotype of -4217 TH-PstI $(\mathrm{OR}=2.27)$, since the +1127 INS-PstI and -4217 TH-PstI markers were in linkage disequilibrium.

If the polymorphism at +1127 INS-PstI increases prostate cancer risk via altered insulin levels, this may explain its lack of association with prostate cancer among the diabetics. The insulin levels of the diabetics can be manipulated by medical intervention, rendering the genotype irrelevant for cancer risk. Other treatment for diabetes, such as weight reduction, could potentially modify the genetic susceptibility to prostate cancer. Since the +1127 INS-PstI marker and its tightly linked VNTR are associated with the risk of diabetes and different alleles are involved in type I vs. type II diabetes (Julier et al, 1991; Lucassen et al, 1993; Bennett and Todd, 1996; Ong et al, 1999; Le Stunff et al, 2000), the allele frequencies of +1127 INS-PstI could potentially be affected by the cause and type of diabetes in both the diabetic cases and controls. The association between prostate cancer and the +1127 INS-PstI marker could be muddled in the diabetics - a heterogeneous group with diverse aetiology, type, and treatment of diabetes as well as endogenous and exogenous insulin. The nondiabetics were simply a group without the complications from a complex disease.

Unlike the Black and Caucasian years, a negative association between the CC genotype and prostate cancer was observed among the Hispanics. This could be because of small sample size or a population stratification bias. We examined for Hardy-Weinberg equilibrium of the genotype frequencies of +1127 INS-PstI by the likelihood ratio test among the controls (Lange, 1997). HardyWeinberg equilibrium was found in both the Caucasians and Blacks, but not in the Hispanic population, in which the frequency of the homozygous TT was higher than expected $(P<0.0001)$. Population admixture, one of the factors that could alter allele frequencies in the Hispanics, may cause biased results in association studies (Ewens and Spielman, 1995).

It is interesting that although the polymorphism at +1127 INSPstI increased the risk for prostate cancer, it was associated with favourable clinical characteristics of the tumour. After adjusting for frequency of physical examination by a clinician, a proxy for access to health care, the CC genotype was associated with late age at diagnosis and low Gleason score. The results suggest that genetic effects take time to accumulate and manifest while affecting the prostate tissue slowly. Alternatively, the age-dependent penetrance of INS may be elevated through interaction with some unknown ageing factors.

Our data suggest that the insulin gene plays a role in the aetiology of prostate cancer. Given the high prevalence of the homozygous CC genotype ( $>60 \%$ in this study population), its population attributable risk can be high. Moreover, given its association with late age of onset of low-grade prostate tumors, the polymorphism at +1127 INS-PstI may contribute to the unique features of prostate cancer that are not seen in other cancers, namely the high prevalence of latent and indolent cancers and the dramatic increase in incidence with age.

Finally, although the polymorphisms of INS have been studied for their roles in diabetes and obesity (Julier et al, 1991; Lucassen et al, 1993; Bennett and Todd, 1996; Ong et al, 1999), this is the first published report on the association between the INS gene and risk of cancer. As a result of our small sample size, our results need to be replicated by population-based studies with a sample size sufficient to confirm various subgroup associations. Another limitation of this study is that fasting blood samples and hence insulin levels were not available. We were not able to examine the hypothesis that the disease association of the polymorphism at +1127 INS-PstI is mediated through altered insulin levels. The available data in the literature have shown that (a) high insulin or C-peptide levels (an indicator for the pancreatic secretion of insulin) are associated with increased risk of cancer (e.g. prostate, colon, breast, and endometrial cancer) (Maggino et al, 1993; Gamayunova et al, 1997; Troisi et al, 1997; Del Giudice et al, 1998; Schoen et al, 1999; Josefson, 2000; Kaaks et al, 2000; Hsing et al, 2001; Yang et al, 2001; Goodwin et al, 2002), (b) there is a relationship between the VNTR allelic variation and INS expression and/or production (Lucassen et al, 1995; Bennett and Todd, 1996; Le Stunff et al, 2000), and (c) there appears to be an 
association between a SNP tightly linked with the VNTR and the risk of prostate cancer. Future studies on cancer should examine comprehensively the inter-relationships among fasting insulin levels, insulin sensitivity, polymorphisms of the INS gene (either the VNTR or one of the surrogate SNPs), and risk of cancer.

\section{ACKNOWLEDGEMENTS}

This work was supported by the Albert Einstein Comprehensive Cancer Center (P30 CA13330) as well as the General Clinical Research Center (RR-12248), and Public Health Service Grant R01 CA64247, National Cancer Institute, National Institutes of Health, Department of Health and Human Services.

\section{REFERENCES}

Bennett ST, Todd JA (1996) Human type 1 diabetes and the insulin gene: principles of mapping polygenes. Annu Rev Genet 30: 343-370

Chan JM, Stampfer MJ, Giovannucci E, Gann PH, Ma J, Wilkinson P, Hennekens CH, Pollak M (1998) Plasma insulin-like growth factor-I and prostate cancer risk: a prospective study. Science 279: 563-566

Chokkalingam AP, Pollak M, Fillmore C-M, Gao Y-T, Stanczyk FZ, Deng J Sesterhenn IA, Mostofi FK, Fears TR, Madigan P, Ziegler R-G, Fraumeni JF, Hsing AW (2001) Insulin-like growth factors and prostate cancer: a population-based case-control study in China. Cancer Epidemiol Biomarkers Prev 10: $421-427$

Cox NJ, Bell GI, Xiang K-S (1988) Linkage disequilibrium in the human insulin/insulin-like growth factor II region of human chromosome 11. Am J Hum Genet 43: 495-501

D’Amico AV, Whittington R, Malkowicz B, Schultz D, Blank K, Broderick GA, Tomaszewski JE, Renshaw AA, Kaplan I, Beard CJ, Wein A (1998) Biochemical outcome after radical prostatectomy, external beam radiation therapy, or interstitial radiation therapy for clinically localized prostate cancer. J Am Med Assoc 280: 969-974

Del Giudice ME, Fantus IG, Ezzat S, McKeown-Eyssen G, Page D, Goodwin PJ (1998) Insulin and related factors in premenopausal breast cancer risk. Breast Cancer Res Treat 47: 111-120

Denton RM, Tavare JM (1995) Does mitogen-activated-protein kinase have a role in insulin action? The cases for and against. Eur J Biochem 227: $597-611$

Devlin B, Risch N (1995) A comparison of linkage disequilibrium measures for fine-scale mapping. Genomics 29: 311-322

Efstratiadis A (1998) Genetics of mouse growth. Int J Dev Biol 42: 955-976

Ewens WJ, Spielman RS (1995) The transmission/disequilibrium test: history, subdivision, and admixture. Am J Hum Genet 57: 455-464

Gamayunova VB, Bobrov Y, Tsyrlina EV, Evtushenko TP, Berstein LM (1997) Comparative study of blood insulin levels in breast and endometrial cancer patients. Neoplasma 44: 123-126

Goodwin PJ, Ennis M, Pritchard KI, Trudeau ME, Koo J, Madarnas Y, Hartwick W, Hoffman B, Hood N (2002) Fasting insulin and outcome in early-stage breast cancer: results of a prospective cohort study. J Clin Oncol 20: $42-51$

Grimberg A, Cohen P (2000) Role of insulin-like growth factors and their binding proteins in growth control and carcinogenesis. J Cell Physiol 183: $1-9$

Hsing AW, Chua Jr S, Gao Y-T, Gentzschein E, Chang L, Deng J, Stanczyk FZ (2001) Prostate cancer risk and serum levels of insulin and leptin: a population-based study. J Natl Cancer Inst 93: 783-789

Josefson D (2000) High insulin levels linked to deaths from breast cancer. $\mathrm{Br}$ Med J 3203: 1496 [News].

Julier C, Hyer RN, Davies J, Merlin F, Soularue P, Briant L, Cathelineau G, Deschamps I, Rotter JI, Frogue P, Boitard C, Bell JI and Lathrop GD (1991) Insulin-IGF2 region on chromosome $11 \mathrm{p}$ encodes a gene implicated in HLA-DR4-dependent diabetes susceptibility. Nature 354: $155-159$

Kaaks R, Toniolo P, Akhmedkhanov A, Lukanova A, Biessy C, Dechaud H, Rinaldi S, Zeleniuch-Facquotte A, Shore RE, Riboli E (2000) Serum C-peptide, insulin-like growth factor (IGF)-I, IGF-binding proteins, and colorectal cancer risk in women. $J$ Natl Cancer Inst 92: $1592-1600$

Kanety H, Madjar Y, Dagan Y, Levi J, Papa MZ, Pariente C, Goldwasser B, Karasik A (1993) Serum insulin-like growth factor-binding protein-2 (IGFBP-2) is increased and IGFBP-3 is decreased in patients with prostate cancer: correlation with serum prostate-specific antigen. J Clin Endocrinol Metab 77: 229-233

Kattan MW, Stapleton AMF, Wheeler TM, Scardino PT (1997) Evaluation of a nomogram used to predict the pathological stage of clinically localized prostate carcinoma. Cancer 79: $528-537$
Kennedy GC, German MS, Rutter WJ (1995) The minisatellite in the diabetes susceptibility locus IDDM2 regulates insulin transcription. Nat Genet 9: $293-298$

Khandwala HM, McCutcheon IE, Flyvbjerg A, Friend KE (2000) The effects of insulin-like growth factors on tumorigenesis and neoplastic growth Endo Rev 21: 215-244

Lange K. (1997). Mathematical and Statistical Methods for Genetic Analysis. New York: Springer.

Le Stunff C, Fallin D, Schork NJ, Bougnères P (2000) The insulin gene VNTR is associated with fasting insulin levels and development of juvenile obesity. Nat Genet 26: 444-446

Lucassen AM, Julier C, Beressi J-P, Boitard C, Froguel P, Lathrop M, Bell JI (1993) Susceptibility to insulin dependent diabetes mellitus maps to a $4.1 \mathrm{~kb}$ segment of DNA spanning the insulin gene and associated VNTR. Nat Genet 4: $305-310$

Lucassen AM, Screaton GR, Julier C, Elliott TJ, Lathrop M, Bell JI (1995) Regulation of insulin gene expression by the IDDM associated, insulin locus haplotype. Hum Mol Genet 4: 501-506

Maggino T, Marcadella CB, Romagnolo C (1993) The role of insulin and renin in the pathogenesis of hormone-dependent neoplasias. (a). Insulin. Eur J Gynaecol Oncol 14: 131-134

Mantzoros CS, Tzonou A, Signorello LB, Stampfer M, Trichopoulos D, Adami H-O (1997) Insulin-like growth factor 1 in relation to prostate cancer and benign prostatic hyperplasia. Br J Cancer 76: 1115-1118

Moule SK, Denton RM (1997) Multiple signaling pathways involved in the metabolic effects of insulin. Am J Cardiol 80: 41A - 49A

Ong KKL, Phillips DI, Fall C, Poulton J, Bennett ST, Golding J, Todd JA, Dunger DB (1999) The insulin gene VNTR, type 2 diabetes and birth weight. Nat Genet 21: 262-263

Park D, Pandey SK, Maksimova E, Kole S, Bernier M (2000) Akt-dependent antiapoptotic action of insulin is sensitive to farnesyltransferase inhibitor. Biochemistry 39: 12513-12521

Pasquali R, Casimirri F, De Iasio R, Mesini P, Boschi S, Chierici R, Flamia R, Biscotti M, Vicennati V (1995) Insulin regulates testosterone and sex hormone-binding globulin concentrations in adult normal weight and obese men. J Clin Endocrinol Metab 80: 654-658

Powell DR, Suwanichkul A, Cubbage ML, DePaolis LA, Snuggs MB, Lee PDK (1991) Insulin inhibits transcription of the human gene for insulinlike growth factor-binding protein-1. J Biol Chem 266: 18868-18876

Qian H, Hausman DB, Compton MM, Martin RJ, Della-Fera MA, Hartzell DL, Baile CA (2001) TNF $\alpha$ induces and insulin inhibits caspase 3dependent adipocyte apoptosis. Bioch Biophy Res Comm 284: 1176-1183

SAS Institute Inc (1989) SAS/STAT User's Guide, Version 6.Cary, NC: SAS Institute, Inc.

Schoen RE, Tangen CM, Kuller LH, Burke GL, Cushman M, Tracy RP, Dobs A, Savage PJ (1999) Increased blood glucose and insulin, body size, and incident colorectal cancer. J Natl Cancer Inst 91: 1147-1154

Soos M, Whittaker J, Lammers R, Ullrich A, Siddle K (1990) Receptors for insulin and insulin-like growth factor-I can form hybrid dimers. Biochem J 270: $383-390$

Stattin P, Bylund A, Rinaldi S, Biessy C, Dechaud H, Stenman U-H, Egevad L, Riboli E, Hallmans G, Kaaks R (2000) Plasma insulin-like growth factor-I, insulin-like growth factor-binding proteins, and prostate cancer risk: a prospective study. J Natl Cancer Inst 92: 1910-1917

Stead JDH, Jeffreys AJ (2000) Allele diversity and germline mutation at the insulin minisatellite. Hum Mol Genet 9: 713-723

Stephens M, Smith NJ, Donnelly P (2001) A new statistical method for haplotype reconstruction from population data. Am J Hum Genet 68: 978-989

Strain G, Zumoff B, Rosner W, Pi-Sunyer X (1994) The relationship between serum levels of insulin and sex hormone-binding globulin in men: the effect of weight loss. J Clin Endocrinol Metab 79: 1173-1176 
Straus DS (1984) Growth-stimulatory actions of insulin in vitro and in vivo. Endo Rev 5: $356-369$

Troisi R, Potischman N, Hoover RN, Siiteri P, Brinton LA (1997) Insulin and endometrial cancer. Am J Epidemiol 146: 476-482

Van Obberghen E, Gammeltoft S (1986) Insulin receptors: structure and function. Experientia 42: 727-734

Wicksteed B, Herbert TP, Alarcon C, Lingohr MK, Moss LG, Rhodes CJ (2001) Cooperativity between the preproinsulin mRNA untranslated regions is necesary for glucose-stimulated translation. J Biol Chem 276: $22553-22558$
Wolk A, Mantzoros CS, Andersson S-O, Bergstrom R, Signorello LB, Lagiou P, Adami H-O, Trichopoulos D (1998) Insulin-like growth factor 1 and prostate cancer risk: a population-based, case-control study. J Natl Cancer Inst 90: $911-915$

Yang G, Lu G, Jin F, Dai Q, Best R, Shu X, Chen JR, Pan XY, Shrubsole M, Zheng W (2001) Populations-based, case-control study of blood cpeptide level and breast cancer risk. Cancer Epidemiol Biomarkers Prev 10: $1207-1211$

Yu H, Rohan T (2000) Role of the insulin-like growth factor family in cancer development and progression. J Natl Cancer Inst 92: 1472-1489 